\title{
Activation of gonads and disruption of imaginal diapause in the apple blossom weevil, Anthonomus pomorum (Coleoptera: Curculionidae), with juvenoids in laboratory and field trials
}

\author{
JAN ŽĎÁREK', RICHARD ČTVRTEČKA², OLDĚICH HOVORKA' and VLADIMIR KOŠŤÁL \\ 'Insect Chemical Ecology Unit, Institute of Organic Chemistry and Biochemistry, Academy of Sciences of the Czech Republic, \\ Flemingovo nám. 2, 16610 Praha 6, Czech Republic; e-mail: zdarek@uochb.cas.cz \\ ${ }^{2}$ North Bohemian Museum, 46001 Liberec, Czech Republic \\ ${ }^{3}$ Institute of Entomology, Academy of Sciences of the Czech Republic, Branišovská 31, 37005 České Budějovice, Czech Republic; \\ e-mail: kostal@entu.cas.cz.
}

\begin{abstract}
Key words. Ecophysiology, reproduction, diapause, aestivo-hibernation, juvenoids, Anthonomus pomorum, Curculionidae
\end{abstract}
\begin{abstract}
A possibility of using synthetic analogues of juvenile hormone (juvenoids) to disrupt imaginal diapause of the apple blossom weevil, Anthonomus pomorum females was demonstrated. Out of three preparations tested (methoprene, fenoxycarb and W-328) methoprene and fenoxycarb appeared to be effective. Sensitivity to juvenile hormone analogues develops early after imagjnal emergence (even before the female starts to feed) and lasts throughout the whole aestivo-hibernation dormancy. Although the juvenoids could stimulate the onset of oogenesis at any time during diapause, the propensity of the ovaries to form normal eggs developed only during hibernation part of the dormancy; in earlier stages of diapause accumulation of yolk was observed but matured eggs were not produced. Methoprene treatment caused marked increase of locomotory activity accompanied with decrease of dry weight, increase of water content, depletion of trehalose resources, decrease of cold hardiness and, finally, $100 \%$ mortality within four weeks in the weevils treated during their feeding or aestivation stages. Although similar changes were observed in the treated pre-feeding weevils, they later recovered and survived until next spring without apparent loss of cold hardiness. A possibility of designing a control method based on this principle is discussed and the results of small-scale field trials that support its plausibility are reported.
\end{abstract}

\section{INTRODUCTION}

The apple blossom weevil, Anthonomus pomorum (L.) is an important pest of apple trees throughout the Holarctic region (Klemm, 1937; Massee, 1954; Reijbroek, 1983; Wildbolz, 1992). It is a univoltine species with aestivohibernation dormancy (Masaki, 1980). In the spring (March, April) when day temperatures reach certain threshold $\left(5^{\circ}\right.$ for crawling, fooding and mating, and $10^{\circ}$ for flying) the overwintering beetles leave their dormancy sites and search for the host trees where they feed and mate, and the females lay eggs in the blossom buds (Duan et al., 1996). Infested buds become sterile and the blossoms never open. Larval and pupal development proceeds inside the buds and the next generation of beetles emerges in May or June. Young adult weevils feed on the parenchyma of apple leaves for about a month and then leave the trees and search for shelters having a suitable microclimate (bark crevices, soil, litter, etc.), some of them migrating short distances to a nearby forest or hedge. Dormancy includes an obligatory reproductive diapause, during which epigamic behaviour and development of the gonads are suppressed (Čtvrtečka \& Žd'árck, 1992). The dormant beetles show special physiological adaptations (cold hardiness and accumulation of polyols) that are also a part of the diapause syndrome (Koštál \& Šimek, 1996). A period of chilling is necessary for completion of diapause development; thenceforth the beetles are kept inac- tive by cold quiescence until the onset of favourable conditions in the spring.

Availability of a suitable food (sprouting apple tree buds) is a necessary prerequisite for initiation of gonadal development of the females but not for sexual receptivity. The males acquire sexual maturity earlier than females, and the initiation of their postdiapause development does not require food (Čtvrtečka \& Žd'árek, 1992). Little is known about how this reproductive arrest, which may last nearly 10 months, is regulated in the apple blossom weevil.

Diapause supports survival during adverse conditions by halting development at a specifically adapted stage. The fitness of an insect to survive through winter depends on physiological adaptations of the organism to cold (Lee \& Denlinger, 1991 for review). These adaptations are hormonally potentiated and in the case of reproductive diapause, juvenile hormone $(\mathrm{JH})$ and its synthetic analogues and mimics (juvenoids) can precociously terminate the diapause of many insects (Denlinger, 1985). A long time ago it was suggested that juvenoids might be used to control insect pests that undergo an imaginal diapause by interrupting their reproductive arrest during a period unsuitable for reproduction (Bowers \& Blickenstaff, 1966). The idea was attractive because many pest species enter diapause (Tauber et al., 1986), and diapause of many species was thought to be susceptible to disruption (Chippendale, 1982; Staal, 1982). As far as we know, no pest 
control system based on this concept has been field tested for any insect except for a scutellerid bug, Eurygaster integriceps Putzeys (Kontev et al., 1974), in spite of the fact that laboratory experiments demonstrated the ability of $\mathrm{JH}$ and its analogues to precociously terminate diapause in many insects (see Denlinger, 1985 for review). The main reason for the reluctance of researchers to test the practicability of this approach in large scale field experiments could be the fact that relatively high doses per animal are needed to affect diapause development in laboratory tests and the effect is often reversible. The idea was revived by Krysan (1990a,b) who showed in laboratory and field experiments that reproductive diapause in the pear psylla, Cacopsylla pyricola (Foerster) can be precociously terminated by minute amounts of a juvenoidbased insecticide, fenoxycarb.

The present paper reports the results of our study aimed at (i) investigating the possibility of using juvenoids to disrupt imaginal diapause of the apple blossom weevil females in the laboratory and (ii) evaluating possibilities of designing a method based on this principle that could eventually become a viable IPM strategy to control the pest. The efficacy of three selected juvenoids to disrupt diapause was first compared in laboratory tests and the most promising one was chosen for small-scale field trials. In order to better understand the mechanism of artificial interruption of diapause, the effects of a hormonal analogue on changes in some physiological characteristics of dormancy (cold hardiness, water content, dry weight, presence of some cryoprotectants) were also investigated.

\section{MATERIAL AND METHODS}

\section{Insects}

Adult weevils that had emerged from pupae collected in apple tree orchards near Prague, Liberec and České Budejjovice, Czech Republic $\left(49-50.5^{\circ} \mathrm{N}\right)$ were used for all experiments. The beetles were allowed to emerge in rearing cages $(50 \times 50 \times 50$ $\mathrm{cm})$ and, except for the winter season, the cages were kept outdoors in a shaded shelter so that the insects were exposed to natural temperature, humidity and photoperiod. For summer feeding the weevils were offered fresh apple twigs with leaves three times a week for six weeks until all beetles spontaneously terminated their feeding activity and began to seek shelter in the fallen dry leaves to begin their aestivo-hibernation. The weevils were then transferred into $500 \mathrm{ml}$ wax-paper cups filled with dry leaves and the cups were closed with nylon netting and placed in an inverted position over a wet Styrofoam layer to create a humidity gradient inside the cup. At the end of October cups with the beetles were transferred to a dark cabinet with controlled temperature of $3-5^{\circ} \mathrm{C}$.

Adult beetles used for all experiments were grouped in four eco-physiological stages:

Stage 1 - beetles less than $24 \mathrm{~h}$ after eclosion from pupae, without access to food.

Stage 2 - beetles feeding for 7 to 20 days after eclosion.

Stage 3 - aestivating beetles in summer after having been fed ad libitum.

Stage 4 - hibernating beetles in winter.

The exact dates and duration of feeding are specified in the Results.

\section{Juvenoids}

Three preparations with juvenile hormone activity were used: (i) W-328: A carbamate-moiety-based juvenoid ethyl 2-(4[(1,4dioxaspirol[4,5]dec-6-yl)methyl]-phenoxy)ethyl carbamate (Wimmer \& Roman̆uk, 1981), (ii) methoprene: An active ingredient of the commercial juvenoid Altosid ${ }^{\mathbb{B}}$ (Sandoz Crop Protection, Palo Alto, California), and (iii) fenoxycarb: The active ingredient of the commercial insecticide Insegar ${ }^{(8)}$ (Ciba-Geigy, formerly Dr. R. Maag AG, Dielsdorf, Switzerland).

\section{Laboratory tests}

For topical application the juvenoids were dissolved in acetone and applied in the volume of $0.5 \mu \mathrm{l}$ per specimen. Controls were treated with acetone alone. For investigation of ovarial development treated weevils were kept in large petri dishes provided with a water vial and fresh apple tree leaves at $23-25^{\circ} \mathrm{C}$. A week later the weevils were dissected under a stereoscopic microscope and the degree of ovarian development evaluated according to a classification scale, the stages of which are described in the Results. For evaluation of the effects ovarial indices were calculated for each experimental group based on the mean degree of ovarial activation reached on day 7 after the treatment

For investigation of the survival rate, polyol content, dry weight, water content and cold hardiness, treated weevils were taken at three different eco-physiological stages (1,2 and 3 as described above), treated with either methoprene $(2.5 \mu \mathrm{g})$ or acetone, returned to natural conditions and subjected to procedures that are fully described by Košt'ál \& Šimek (1996).

\section{Ficld trials}

For application to the leaves, methoprene was dissolved in acetone, and emulsified in water in three concentrations $(25,5$ and $\left.1 \mathrm{g.} \mathrm{l}^{-1}\right)$. The preparations were sprayed as $0.01 \%$ Tweenwater emulsion to both sides of the leaves on a twig ca. $50 \mathrm{~cm}$ long bearing approximately 50 leaves. Tween 20 (Fluka AG) was used as an emulsifier. From the amount of emulsion sprayed it was calculated that each square centimetre of the leaf surface received an average of 320,64 and $13 \mu \mathrm{g}$ of the active compound, respectively. The weevils were released to the twigs after the water had evaporated. For the outdoor experiments the treated twigs on apple trees were enclosed in nylon netting before the weevils were released. In the laboratory the treated twigs were kept in a jar with water in $50 \times 50 \times 50 \mathrm{~cm}$ breeding cages.

\section{Statistics}

Dependence of probability of activation of gonads on two experimental factors (dose and life stages) was modelled using a generalised linear model (GLM) with binomial distribution of dependent variable and logit link function (McCullagh \& Nelder, 1989). The test of significance of the factors was based on the analysis of deviance table. A two-tailed t-test was used for the remaining evaluations.

\section{RESULTS}

\section{Morphological effects of juvenoids on the female gonads}

Precocious development of the ovaries induced by juvenile hormone analogues applied before and during the feeding period (in May and June, stages 1 and 2), and during the aestivation period (from July to October, stage 3) was atypical in comparison with normal development of the ovaries occurring after aestivo-hibernation in spring. Three distinct stages of growth and development 


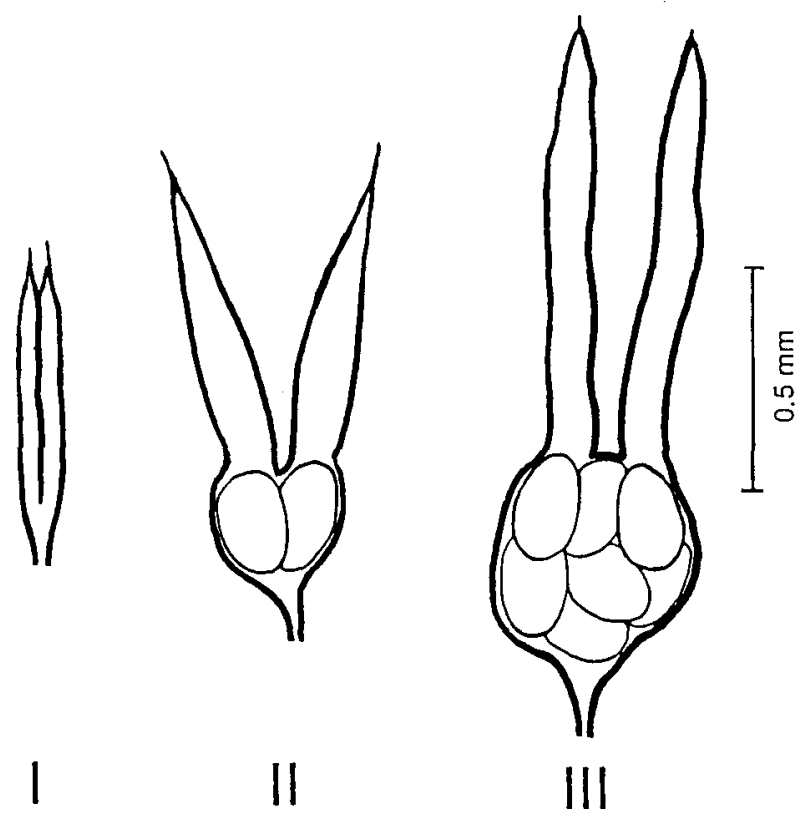

Fig. 1. Stages of the ovarioles after activation by a juvenoid during the aestivation period.

of the ovaries could be distinguished. The ovarioles of stage I were short, undifferentiated and entirely transparent. The ovaries of other stages had no parallel with normal developmental stages as classified by Čtvrtečka \& Žd'árek (1992). The ovarioles of stage II were elongated and wider than those of stage I, their vitellarium was not differentiated and the calyx slightly enlarged to the size of a ripe oocyte. The ovarioles of stage III were still larger than those of stage II, the vitellarium showed no differentiation of oocytes but appeared to be packed with a mass of yolk. The yolk may have partially descended to the calyx where the oocytes were enveloped with thin and indistinct membranes (Fig. 1). The oocytes never developed into ripe eggs, even if the females were offered apple tree leaves for feeding. On the contrary, if development of the gonads was activated by a juvenoid during the overwintering period (from November to March, stage 4) the induced changes were comparable to ovarian development occurring during natural reactivation in the spring, i.e. vitellogenesis began and if the females were offered apple tree buds for feeding, the eggs developed. Unfed females did not develop eggs.

\section{Comparison of the effects of three juvenoids on activation of the ovaries}

The objective was to select the most suitable JH analogue for field experiments out of three preparations that were either available commercially (fenoxycarb, methoprene) or locally synthesised in large quantities as a potential insecticide (W-328). The juvenoids were topically applied in two doses $(0.5$ and $2.5 \mu \mathrm{g})$ to freshly emerged stage 1 females and stage 2 females that had been allowed to feed on apple tree leaves for 10 days before application (Table 1). All three juvenoids caused activation of the gonads both in pre-feeding and feeding females, but the latter were significantly more sensitive to the juvenoids than the freshly eclosed females. Among the three juvenoids, methoprene and fenoxycarb appeared to be more effective than W-328. Because the ovarial indices of females treated with the lower dose of methoprene were higher than in the females treated with the same dose of the other two juvenoids, methoprene was selected for all further experiments.

\section{Changes in sensitivity to methoprene during adult stages of the female}

Methoprene was applied in two concentrations to the female weevils at four adult stages of their life cycle, namely to freshly emerged (pre-feeding) females, females after 10 days of feeding, inactive females during their aestivation period in September, and inactive females during their hibernation period in November (Table 2). Except for the lower dose $(0.5 \mu \mathrm{g})$ applied to freshly eclosed females (stage 1), application of either dose caused ovarial activation in practically all females treated at later developmental stages (2, 3 and 4 ). Thus the effect of dose was not significant at the level $0.05(\mathrm{~F}=7.12, \mathrm{P}=0.76)$, while the effect of stage was $(F=11.58, P=0.037)$. In other words, the probability of activation of gonads of stage 1 females differs from that of females of later life stages. Some degree of ovarial activation was also observed in the acetone-treated weevils and also in nontreated overwintering females (not shown in the table) indicating a low degree of spontaneous activation before and during diapause. Mortality of weevils treated with

TABLE 1. The effects of three juvenoids on activation of gonads of $A$. pomorum females before and after maturation feeding. (The degree of activation was evaluated 7 days after the treatment.)

\begin{tabular}{|c|c|c|c|c|c|}
\hline \multirow[t]{2}{*}{ Compound } & \multirow[t]{2}{*}{ Dose $(\mu g)$} & \multicolumn{2}{|c|}{ Number of affected females/ $\mathrm{N}$ treated } & \multicolumn{2}{|c|}{ Ovarial index ${ }^{\prime}$ of females treated } \\
\hline & & $\overline{\text { before }}$ & after feeding ${ }^{2}$ & before & after feeding $^{2}$ \\
\hline FENOXYCARB & $\begin{array}{l}0.5 \\
2.5\end{array}$ & $\begin{array}{r}9 / 30 \\
18 / 30\end{array}$ & $\begin{array}{l}18 / 30 \\
29 / 29\end{array}$ & $\begin{array}{l}1.30 \\
1.66\end{array}$ & $\begin{array}{l}1.66 \\
2.48\end{array}$ \\
\hline METHOPRENE & $\begin{array}{l}0.5 \\
2.5\end{array}$ & $\begin{array}{l}18 / 30 \\
20 / 30\end{array}$ & $\begin{array}{l}29 / 30 \\
29 / 30\end{array}$ & $\begin{array}{l}1.60 \\
1.66\end{array}$ & $\begin{array}{l}2.17 \\
2.33\end{array}$ \\
\hline$W-328$ & $\begin{array}{l}0.5 \\
2.5\end{array}$ & $\begin{array}{r}8 / 30 \\
17 / 30\end{array}$ & $\begin{array}{l}10 / 15 \\
13 / 30\end{array}$ & $\begin{array}{l}1.27 \\
1.56\end{array}$ & $\begin{array}{l}1.67 \\
1.43\end{array}$ \\
\hline ACETONE (control) & $0.5 \mu \mathrm{l}$ & $0 / 30$ & $1 / 30$ & 1.00 & 1.06 \\
\hline
\end{tabular}

\footnotetext{
'Mean degree of ovarial activation according to the scale explained in the methods.
}

${ }^{2}$ After 10 days of feeding on fresh apple tree leaves. 
TABLE 2. The effects of methoprene on activation of gonads of A. pomortm females in different adult stages. (The degree of activation was evaluated 7 days after treatment.)

\begin{tabular}{llcl}
\hline Adult life stage & Dose $(\mu \mathrm{g})$ & Number of affected females/N & Ovarial index $^{1}$ \\
\hline Freshly emerged (May) & 0.5 & $7 / 15$ & 1.47 \\
(Stage 1) & 2.5 & $13 / 15$ & 1.87 \\
& Acetone control & $0 / 15$ & 1.00 \\
After 10 days of feeding (July) & 0.5 & $15 / 15$ & 2.27 \\
(Stage 2) & 2.5 & $15 / 15$ & 2.47 \\
& Acetone control & $2 / 15$ & 1.13 \\
During aestivation (Sept.) & 0.5 & $14 / 15$ & 1.93 \\
(Stage 3) & 2.5 & $14 / 15$ & 2.13 \\
& Acetone control & $2 / 15$ & 1.13 \\
During hibernation (Nov.) & 0.5 & $14 / 15$ & 1.93 \\
(Stage 4) & 2.5 & $15 / 15$ & 2.07 \\
& Acetone control & $5 / 15$ & 1.33 \\
\hline
\end{tabular}

${ }^{1}$ Mean degree of ovarial activation according to the scale explained in the methods.

$2.5 \mu \mathrm{g}$ methoprene at stage 1 differed markedly from that of weevils treated at stages 2 and 3 , but did not differ from mortality of controls treated with acetone at the same stage (Fig. 2). While weevils of stages 2 and 3 did not survive after methoprene treatment for more than a month, ca. $25 \%$ of beetles treated at stage 1 survived till the next spring, and so did the controls.

\section{The effects of methoprene applied to apple tree leaves}

Freshly eclosed weevils were allowed to feed on apple tree leaves treated with three different doses $(320,64$ and $13 \mu \mathrm{g} . \mathrm{cm}^{-2}$ of the leaf surface) of methoprene, and the degree of activation of their gonads was evaluated and compared with that of females treated topically with $2.5 \mu \mathrm{g}$ of methoprene and allowed to feed on untreated leaves. Acetone-treated females feeding on untreated leaves served as controls (Table 3). All doses of methoprene applied to the leaves on which the weevils fed caused activation of the gonads in the majority of the females, no matter if the cage with the apple tree twigs was kept indoors or if the treatment was done in the orchard using leaves of a growing tree. Consistent with the previous experiments, all feeding females treated topically with methoprene showed activated gonads while none from the acetone treated group did so.

\section{The effect of methoprene on some physiological attributes of dormancy}

Substantial differences of the juvenoid effect on cold hardiness (measured as a capacity to survive exposure to low temperature for 5 days) were observed between freshly emerged, pre-feeding weevils (stage 1) and postfeeding aestivating ones (stage 3 ) (Table 4). Application of methoprene to the beetles of stage 1 had no effect on their cold hardiness assessed during overwintering (i.e. cight months after treatment). In the beetles of stage 2, our original intention was to assess cold hardiness also during the most relevant, hibernation part of the life cycle. But no beetle of stage 2 survived methoprene treatment till winter (Fig. 2). Thus, in the beetles of stage 3 we assessed cold hardiness only one week after treatment when the beetles were still in aestivation. Substantially impaired survival was observed in the methoprene-treated group in comparison with the acetone-treated controls after exposure to $-11^{\circ} \mathrm{C}$ (Table 4$)$.

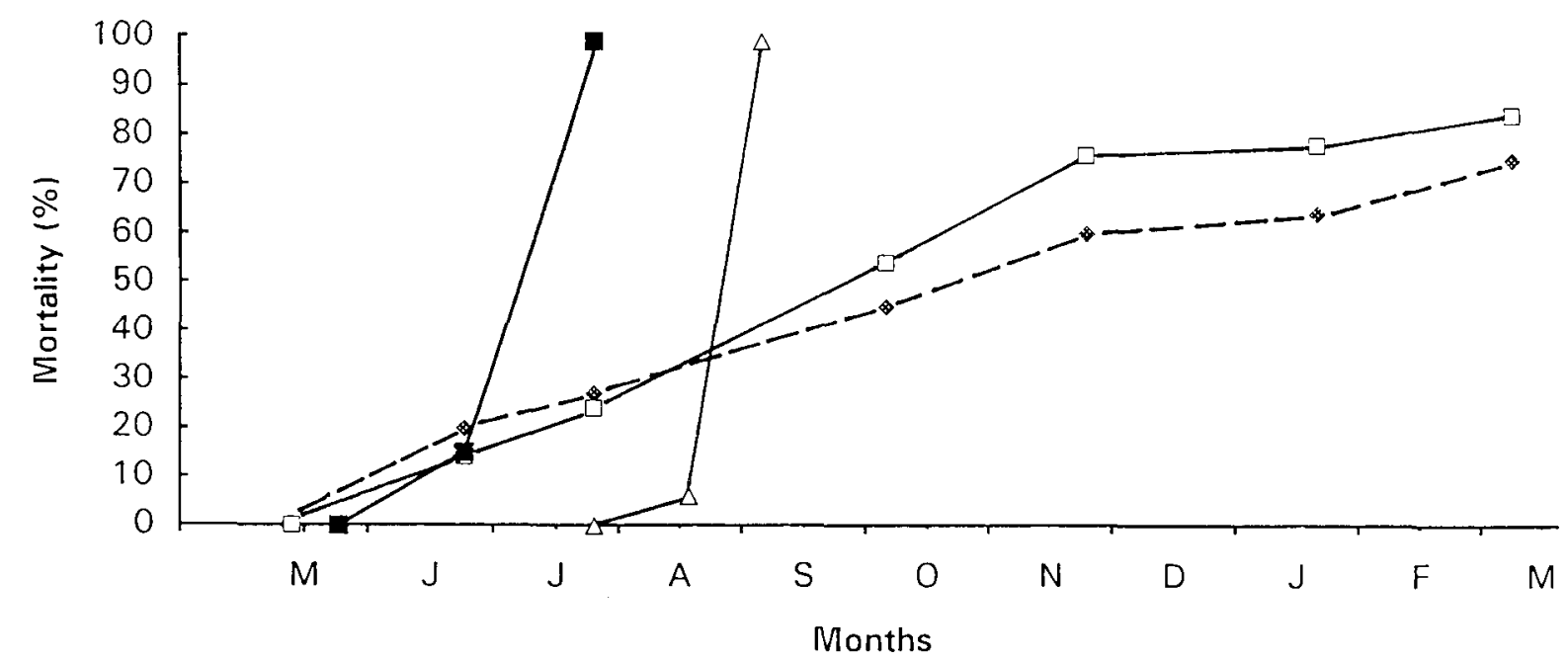

Fig. 2. Cumulative mortality of adult $A$. pomornm weevils treated with methoprene $(2.5 \mu \mathrm{g})$ (solid lines) at the life stage 1 ( $\square$, $\mathrm{N}=350), 2(\boldsymbol{\square}, \mathrm{N}=400)$ and $3(\triangle, N=300)$ and acetone $(0.5 \mu \mathrm{l})$ (broken line, $\mathrm{N}=1080)$. 
TABLE 3. The effects of methoprene on activation of gonads of $A$. pomorum females that were allowed to feed on apple tree leaves treated with different doses of the juvenoid.

\begin{tabular}{llll}
\hline Experimental group & Dose $\left(\mu \mathrm{g} . \mathrm{cm}^{-2}\right)$ & Number of affected females/N & Ovarial index $^{\prime}$ \\
\hline Weevils on treated leaves & 320 & $38 / 42$ & 1.97 \\
(indoors) & 64 & $42 / 43$ & 2.11 \\
& 13 & $30 / 31$ & 1.81 \\
Weevils on treated leaves & 320 & $48 / 50$ & 2.04 \\
(outdoors) & 64 & $42 / 50$ & 1.94 \\
& 13 & $28 / 36$ & 1.78 \\
Acetone treated weevils on untreated leaves & 0 & $0 / 40$ & 1.00 \\
(outdoors) & & $56 / 56$ & 2.34 \\
Weevils topically treated on untreated leaves & $2.5 \mu \mathrm{g}$ & & \\
(outdoors) & & &
\end{tabular}

'Mean degree of ovarial activation according to the scale explained in the methods.

Water content was significantly elevated in weevils of all three life stages one week after treatment with methoprene. Dry weight decreased significantly only in beetles of stages 1 and 2; a similar trend was apparent but insignificant ( $\mathrm{p}=0.13$, t-test) also in the beetles of stage 3 (Table 5).

The content of glucose was insensitive to the treatment with methoprene in the beetles of all three life stages (Table 6). Depletion of trehalose after treatment with methoprene was observed in the aestivating beetles of stage 3 (Table 6).

Behavioural observations. In the control (acetonetreated) or untreated weevils, locomotory activity regularly decreased after termination of feeding; the weevils searched for shelters and ultimately became lethargic. Application of methoprene, both during feeding (stage 2) and during aestivation (stage 3 ), dramatically elevated activity of the beetles. They perpetually walked or flew but did not seek shelters. Beetles treated with methoprene at stage 1 behaved normally.

\section{DISCUSSION}

It is generally understood that reproductive diapause in female insects is caused by a lack of hormones that regulate gonadal functions and epigamic behaviour (Denlinger, 1985), and addition of this hormone or its analogues after a certain refractory phase following emergence can induce reproduction. Reproductive diapause may occur only in females, while males of some species are able, under favourable conditions, to mate at any time after their gonads become mature, if receptive females are available (Žd'árek \& Kontev, 1975). If reproductive diapause does occur in the male, it is usually controlled by the same endocrine mechanism as in the females, i.e. by a shut-down of the corpora allata (Pener, 1992; Watanabe \& Tanaka, 1998).

In the present study the potency of exogenous juvenoids to disrupt obligatory diapause of apple blossom weevil females was investigated. Our earlier results indicated that female weevils were indeed sensitive to the juvenoid methoprene (Čtvrtečka \& Žd'árek, 1992). The analogue accelerated ovarian development and sexual

TABLE 4 . The effects of methoprene $(2.5 \mu \mathrm{g})$ on cold hardiness, measured as a capacity to survive the exposure to low temperature for 5 days, in $A$. pomorum adults of three different life stages.

\begin{tabular}{|c|c|c|c|c|}
\hline \multirow{2}{*}{ Life stage when treated } & \multirow{2}{*}{ Treatment } & \multicolumn{2}{|c|}{ Exposure for 5 days } & \multirow{2}{*}{ Survival $(\%)^{\prime}$} \\
\hline & & at temp. $\left({ }^{\circ} \mathrm{C}\right)$ & during stage ${ }^{2}$ & \\
\hline \multirow{6}{*}{$\begin{array}{l}\text { Freshly emerged (May) } \\
\text { (Stage 1) }\end{array}$} & methoprene & -15 & hibernation (Dec.) & 90 \\
\hline & & -11 & " & 85 \\
\hline & & -8 & $"$ & 95 \\
\hline & acetone control & -15 & hibernation (Dec.) & 90 \\
\hline & & -11 & $"$ & 95 \\
\hline & & -8 & $"$ & 95 \\
\hline $\begin{array}{l}\text { Feeding (June) } \\
\text { (Stage 2) }\end{array}$ & \multicolumn{4}{|c|}{ not performed due to high mortality } \\
\hline \multirow{6}{*}{ (Stage 3) } & methoprene & -15 & aestivation (Aug.) & 0 \\
\hline & & -11 & $"$ & 50 \\
\hline & & -8 & $"$ & 100 \\
\hline & acetone control & -15 & acstivation (Aug.) & 0 \\
\hline & & -11 & $"$ & 95 \\
\hline & & -8 & $"$ & 100 \\
\hline
\end{tabular}

\footnotetext{
${ }^{1}$ Capability of coordinated movement in twenty individuals/test group was scored a week after exposure to a low temperature.

${ }^{2}$ Note the difference in time interval elapsed from the treatment to the test of cold hardiness: 8 months for stage 1 and 1 week for stage 3.
} 
TABLE 5. The effects of methoprene $(2.5 \mu \mathrm{g})$ on water content and dry weight when applied at different life stages of $A$. pomortum adults. (Evaluation was done 7 days after treatment.)

\begin{tabular}{lllll}
\hline Life stage when treated & Treatment & $\mathrm{N}$ & Water content \% (mean \pm S.D.) & Dry weight $\mu g(m e a n \pm$ S.D.) \\
\hline Freshly eclosed (May) & methoprene & 10 & $66.93 \pm 5.51$ & $1.66 \pm 0.22$ \\
(Stage 1) & acetone & 28 & $58.24 \pm 5.81^{* *}$ & $2.21 \pm 0.41^{* *}$ \\
Feeding (June) & methoprene & 10 & $63.19 \pm 4.60$ & $1.59 \pm 0.18$ \\
(Stage 2) & acetone & 11 & $52.16 \pm 4.74^{* *}$ & $2.11 \pm 0.24^{* *}$ \\
Aestivating (Aug.) & methoprene & 10 & $60.75 \pm 4.97$ & $1.71 \pm 0.12$ \\
(Stage 3) & acetone & 10 & $56.80 \pm 3.69^{*}$ & $1.87 \pm 0.29$ \\
\hline
\end{tabular}

Differences are significant at $p<0.05\left({ }^{*}\right)$ and $p<0.01\left({ }^{* *}\right)(t$-test $)$.

maturation in winter and spring (i.e. during and after hibernation), and it did so in the absence of food. Here we have confirmed the previous findings and complemented them with a study of the action of the juvenoid in earlier adult stages of the female's life cycle, namely shortly after the imaginal emergence, during feeding and later in the period of summer inactivity (aestivation). The gonads of a few untreated females showed slightly advanced development in the autumn and winter, indicating that some spontaneous activation of reproductive processes may begin before hibernation. This observation is paralleled by the observation that spermathecae of a small percentage of females (ca. 20\%) dissected in the autumn contained sperm (Čtvrtečka, unpubl.).

Our present results thus indicate that female sensitivity to $\mathrm{JH}$ analogues develops very early in the imaginal stage, even before the female starts to feed, and the period of sensitivity lasts throughout adult life. It indicates that the postemergence refractory phase in the female is very short, if it exists at all. The water content and dry weight of methoprene-treated pre-feeding weevils were also different from those of controls, indicating their physiological responsiveness to the hormonal treatment. However, sensitivity of freshly emerged weevils to juvenoids was lower than in older ones, because the amount of exogenous hormone required to activate the gonads in prefeeding females was higher than in those that had already consumed some food. The low sensitivity of the youngest beetles to the juvenoid was also apparent from mortality data. While feeding and post-feeding (aestivating) weevils invariably died within one month after the treatment, the mortality curve of pre-feeding beetles followed practically the same course as that of acetone-treated controls resulting in a similar proportion of beetles of both groups surviving till next spring.
Although the exogenous hormonal signal can stimulate the onset of oogenesis at any time, the propensity of the ovaries to produce matured eggs in response to the hormonal stimulus develops much later, namely during the hibernation part of the dormancy. In earlier stages only accumulation of yolk in the ovarioles can be observed.

Besides the effects of the $\mathrm{JH}$ analogue on the gonads we also investigated its effects on some other physiological characteristics of dormancy. Cold hardiness is one of the important aspects of the diapause syndrome in $\mathrm{A}$. pomorum. It develops during the aestivation part of dormancy and further increases during hibernation, after the onset of low autumnal temperatures (Koštál \& Šimek, 1996). Only the weevils treated with methoprene at stage 1 survived till hibernation and their winter cold hardiness was similar to controls. The weevils treated with methoprene during aestivation (stage 3) decreased their cold hardiness within one week, which suggests that their diapause was disrupted. A similar loss of cold hardiness accompanying artificial termination of adult reproductive diapause by juvenoid treatment was observed in a chrysomelid bectle, Aulacophora nigripennis (Watanabe \& Tanaka, 1998).

The increase of water content and concomitant decrease of dry weight were observed in $A$. pomorum after treatment with juvenoid. Such a pattern of changes again evokes an interpretation that, after the juvenoid treatment, the weevils switched from inactive, energy-saving status typical for diapause to the higher rate of metabolism typical for an active state. This switch was further documented by two additional facts: (1) a markedly elevated locomotory activity in the juvenoid-treated beetles, and (2) depletion of trehalose (a main resource of easily accessible metabolic fuel) in the weevils of stage 3; a similar depletion was not observed in the weevils of stage 2,

TABL: 6. The effects of methoprene $(2.5 \mu \mathrm{g})$ on the trehalose and glucose contents in adult stages of $A$. pomorum. (Contents of the sugars were evaluated 14 days after treatment ${ }^{1}$.)

\begin{tabular}{llll}
\hline Life stage when treated & Treatment & Glucose content $(\mu \mathrm{g} / \mathrm{mg} \mathrm{d.w.})$ & Trehalose content $(\mu \mathrm{g} / \mathrm{mg} \mathrm{d} . \mathrm{w})$. \\
\hline Freshly eclosed (May) & methoprene & 6.3 & 0 \\
(Stage 1) & acetone & 9.6 & 0 \\
Feeding (June) & methoprene & 8.8 & 2.4 \\
(Stage 2) & acetone & 7.1 & 3.0 \\
Aestivating (Aug.) & methoprene & 2.2 & 0 \\
(Stage 3) & acetone & 2.1 & 7.6 \\
\hline
\end{tabular}

'Ten individuals were pooled for each treatment and analysed as one sample using GC-MS technique (Koštál \& Šimek, 1996). 
probably because these weevils could continuously replenish their resources by feeding.

Thus, although activation of gonads and other physiological changes were observed in response to methoprene treatment in the pre-feeding beetles (stage 1), they probably recovered fully later and survived in similar numbers as controls until the next spring having their capacity to overwinter unimpaired. However, from the practical point of view it is important that no beetles of either sex treated at stages 2 and 3 survived the hormonal treatment for more than four weeks. Our data suggest that the treated insects died because metabolism was elevated and no or limited food was supplied.

The outcome of our small-scale field trials implied that the encouraging results obtained in the laboratory could be expected under natural field conditions. However, more extensive field tests are needed to substantiate this argument. Nevertheless, the present results do imply a potential use of pesticides based on juvenoid action for the control of the apple blossom weevils. Juvenoid basedpesticides, such as fenoxycarb (Charmillot \& Pasquier, 1992) or W-328 and related preparations (Kuldová \& Matolín, pers. commun.) have been tested as ovicides for use as an alternative management strategy for a major apple orchard pest, the codling moth (Cydia pomonella). Possibly some such insecticides could be used for combined control of the codling moth and the apple blossom weevil in an IPM programme. Because the flight of first generation moths roughly coincides with the feeding period of newly emerged apple blossom weevils, both pests could possibly be treated with a single application.

ACKNOWLEDGEMENTS. We thank D.L. Denlinger for critical reading of the manuscript, $Z$. Wimmer for the gift of the juvenoid W-328 and P. Simek and A. Heydová for chemical analyses of insect samples. This research was supported by the grant no. A655118 from the Grant Agency of the Academy of Sciences of the Czech Republic.

\section{REFERENCES}

Bowers W.S. \& BlıckinstAFF C.C. 1966: Hormonal termination of diapause in the alfalfa weevil. Science (Washington) 154: 1673-1674.

Chinkmillot P.-J. \& Pasquier D. 1992: Modification de la fertilité du carpocapse Cydia pomonella à la suite du contact des adultes avec un régulateur ou un inhibiteur de croissance d'insectes. Entomol. Exp. Appl. 63: 87-93.

CHIPPENDALE G.M. 1982: Insect diapause, the seasonal synchronization of life cycles, and management strategies. Entomol. Exp. Appl. 31: 24-35.

ČTVRTEČKA R. \& ŽD̆ÁAREK J. 1992: Reproductive diapause and its termination in the apple blossom weevil (Anthonomus pomorum) (Coleoptera, Curculionidae). Acta Entomol. Bohemoslov. 89: 281-286.

DENLINGER D.L. 1985: Hormonal control of diapause. In Kerkut G.A. \& Gilbert L.I. (eds): Comprehensive Insect Physiology,
Biochemistry and Pharmacology. Vol. 8. Pergamon Press, Oxford, pp. 353-412.

DunN J.J., Wlibier D.C., HiRs B. \& Dorn S. 1996: Spring behavioral patterns of the apple blossom weevil. Entomol. Exp. Appl. 79: 9-17.

DUAN J.J., WIBBRR D.C. \& DORN S. 1998: Flight behaviour of pre- and postdiapause apple blossom weevils in relation to ambient temperature. Entomol. Exp. Appl. 88: 97-99.

KLEMM M. 1937: Der gegenwartige Stand der Frage über die Schädlichkeit des Apfleblutenstechers. Z. Angew. Entomol. 23: 223-264.

Kontev C., Seinal. F., Ž ̇̇̉rfik J. \& Ondríčlk J. 1974: The possible control of Eurygaster integriceps (Heteroptera, Scutelleridae) by treating eggs and adults with juvenoids. Acta Entomol. Bohemoslov. 71: 72-79.

KoŠìL V. \& ŠimLK P. 1996: Biochemistry and physiology of aestivo-hibernation in the adult apple blossom weevil, Anthonomus pomorum (Coleoptera: Curculionidae). J. Insect Physiol. 42: 727-734.

KRYSAN J.L. 1990a: Fenoxycarb and diapause: A possible method of control for pear psylla (Homoptera: Psyllidae). $J$. Econ. Entomol. 83: 293-299.

KRYSAN J.L. 1990b: Premature termination of reproductive diapause by a juvenile hormone mimic: A possible control strategy for pear psylla. In Hoshi M. \& Yamashita O. (eds): $A d$ vances of Invertebrate Reproduction 5. Elsevier Science Publishers, pp. 387-392.

LeE R.E. \& Denlinger D.L. 1991 (eds): Insects at Low Temperature. Chapman and Hall, New York, 513 pp.

MAsıkı S. 1980: Summer diapause. Annu. Rev. Entomol. 25: $1-25$.

MAsseE A.M. 1954: The Pests of Fruits and Hops. 3rd ed. Garden City Press, London, $338 \mathrm{pp}$.

McCullngh P. \& Nelder J.A. 1989: Generalized Linear Models. 2nd ed. Chapman and Hall, London, $511 \mathrm{pp}$.

Pener M.P. 1992: Environmental cues, endocrine factors, and reproductive diapause in male insects. Chronobiol. Int. 9: 102-113.

Ri:JisRolk P. 1983: The relation between attack and damage by the apple blossom weevil, Anthonomus pomorum (L.). Med. Fac. Landbouww. Rijksuniv. Gent 48: 287-291.

STAAL G.B. 1982: Insect control with growth regulators interfering with the endocrine system. Entomol. Exp. Appl. 31: $15-23$.

TAuber M.J, TAubler C.A. \& MAsAki S. 1986: Seasonal Adaptations of Insects. Oxford University Press, New York, 411 pp.

WАTANABг: M. \& TАNАKА K. 1998: Effect of juvenile hormone analogs on diapause termination and myo-inositol content in Aulacophora nigripennis adults (Coleoptera: Chrysomelidae) Appl. Entomol. Zool. 33: 259-262.

WILDBolz T. 1992: Pest situation in orchards evolving: natural and man made factors. Acta Phytopathol. Entomol. Hung. 27: 669-678.

Wimmi:R Z. \& Rom^ÑuK M. 1981: The synthesis of biologically active 2-(4-hydroxybenzyl)-1-cyclohexanone derivatives. Coll. Czech. Chem. Commun. 46: 2573-2586.

ŽD̆AREK J. \& Kontev C. 1975: Some ethological aspects of reproduction in Eurygaster integriceps (Heteroptera, Scutelleridae). Acta Entomol. Bohemoslov. 72: 239-248.

Received March 5, 1999; accepted May 12, 1999 